\title{
CHẤT LƯợNG CUỘC SỐNG NGƯờI BỆNH TĂNG HUYÊTT ÁP
}

\section{TÓM TẮT}

Mở đầu: Tăng huyết áp (THA) là bệnh lý mạn tính, triệu chứng của bệnh thường diễn tiến âm thầm làm ảnh hưởng đến sức khỏe, sức lao động và làm ảnh hưởng đến chất lượng cuộc sống (CLCS) của người bệnh. Chất lượng cuộc sống của người bệnh THA giảm dần do biến chứng của bệnh, bệnh lý kèm theo, tác dụng phụ của thuốc điều trị và nhận thức bệnh tật của người bệnh. Do đó chất lượng cuộc sống người bệnh THA là một trong những tiêu chí ngày càng được lưu tâm hơn.

Mục tiêu: Khảo sát chất lượng cuộc sống người bệnh tăng huyết áp đang điều trị tại Khoa Nội Tim Mạch bệnh viện Đa Khoa Thành Phố Cần Thơ.

Đối tượng - Phương pháp nghiên cứu:Cắt ngang mô tả 334 người bệnh THA đang điều trị tại khoa Nội Tim Mạch bệnh viện Đa khoa Thành Phố Cần Thơ thời gian nghiên cứu từ tháng 11/2013 đến tháng 5/2014. Sử dụng bộ câu hỏi SF-36.

Kết quả: 334 người bệnh tham gia nghiên cứu thì điểm số trung bình của sức khỏe thể chất là $30.8 \pm$ 5.2 , sức khỏe tinh thần là $32.0 \pm 7.1$, chất lượng cuộc sống $31.4 \pm 4.4$.

Kết luận: Người bệnh có chất lượng cuộc sống thấp theo thời gian THA, kiểm soát huyết áp và tổn thương cơ quan đích. Do đó, việc xét CLCS khi chăm sóc và điều trị bệnh THA là vấn đề ngày càng được quan tâm.

*Từ khóa: Chất lượng cuộc sống, tăng huyết áp.

\section{SUMMARY}

\section{HEALTH - RELATED QUALITY OF LIFE IN HYPERTENSIVES}

\section{Background: \\ Objective: \\ Method: \\ Result: \\ Conclusion:}

*Keywords: Health - related quality of life, hypertension.
Nguyê̂n Hoàng Định*, Huỳnh Bích Nhiều**

\section{1. ĐẠTT VẤN ĐỀ}

THA là bệnh lý rất thường gặp trong cộng đồng, và là yếu tố nguy cơ tim mạch liên quan đến bệnh mạch vành, suy tim, bệnh mạch máu não và bệnh thận mạn tính [4]. CLCS của người bệnh THA giảm dần do biến chứng của bệnh, bệnh lý kèm theo, tác dụng phụ của thuốc điều trị và nhận thức bệnh tật của người bệnh [12].Trên thế giới có rất nhiều đề tài nghiên cứu liên quan đến CLCS, trong khi đó những nghiên cứu trong nước liên quan đến CLCS bệnh THA còn hạn chế. Do đó nghiên cứu này được tiến hành với mong muốn khảo sát CLCS người bệnh THA để việc chăm sóc sức khỏe người bệnh được sát hợp hơn. Mục đích nghiên cứu của chúng tôi là:

Khảo sát CLCS người bệnh THA đang điều trị tại Khoa Nội Tim Mạch bệnh viện Đa Khoa Thành Phố Cần Thơ."

\section{2. ĐỐI TƯợNG - PHƯƠNG PHÁP NGHIÊN CÚU}

2.1. Phương pháp nghiên cứu:.Cắt ngang mô tả 334 người bệnh THAđang điều trị tại khoa Nội Tim Mạch bệnh viện Đa khoa Thành Phố Cần Thơ. Thời gian nghiên cứu từ tháng $11 / 2013$ đến tháng $5 / 2014$. Sử dụng bộ câu hỏi khảo sát SF-36.

\subsection{Xử lí số liệu}

Nhập dữ liệu bằng phần mềm Epidata 3.1

Xử lý và phân tích dữ liệu bằng phần mềm Stata 12.0

Thống kê phân tích - kiểm định sự khác biệt:

+ Biến phụ thuộc là biến định lượng có phân phối bình thường và

- Biến độc lập là biến nhị giá: dùng phép kiểm $\mathrm{t}$

- Biến độc lập là biến danh định và thứ tự: dùng kiểm định ANOVA.

+ Đối với biến định lượng có phân phối không bình thường.

- Biến độc lập là biến nhị giá: dùng phép kiểm phi tham số Mann-Whitney.

- Biến độc lập là biến danh định hay thứ tự: dùng phép kiểm Kruskal-Wallis.

\footnotetext{
* Bệnh viện Đại hoc Y Dược TPHCM

** Bệnh viện Đa Khoa Thành Phố Cần Tho Người chịu trách nhiệm khoa học: TS. Nguyễn Hoàng Định Ngày nhận bài: 10/01/2016 - Ngày Cho Phép Đăng: 24/02/2016

Phản Biện Khoa học: PGS.TS. Đặng Ngọc Hùng
} GS.TS. Bùi Đức Phú 
Xác định điểm số tám lĩnh vực và hai thành phần sức khỏe thể chất và sức khỏe tinh thần trong bảng câu hỏi khảo sát sức khỏe tổng quát SF- 36phiên bản Việt Nam bằng phần mềm tính điểm Quality MetricHealth Outcomes Scoring Software 4.5.1.

\section{KẾT QUẢ NGHIÊN CÚU}

334 người bệnh được khảo sát từ tháng 11/2013 đến tháng $5 / 2014$

\section{Bảng 1: Đặc điểm dân số học}

\begin{tabular}{|c|c|c|}
\hline \multicolumn{3}{|l|}{ Biến số } \\
\hline Giới & & \\
\hline Nũ̃ & 228 & 68.26 \\
\hline Nam & 106 & 31.74 \\
\hline \multicolumn{3}{|l|}{ Nhóm tuổi } \\
\hline$<=40$ & 5 & 1.5 \\
\hline 40-59 & 65 & 19.46 \\
\hline $60-79$ & 178 & 53.29 \\
\hline$>=80$ & 86 & 25.75 \\
\hline \multicolumn{3}{|l|}{ Nơi cư trú } \\
\hline Cần thơ & 260 & 77.84 \\
\hline Khác & 74 & 22.16 \\
\hline \multicolumn{3}{|l|}{ Trình độ học vấn } \\
\hline Mù chữ & 57 & 17.07 \\
\hline Biết đọc-viết/cấp 1 & 19 & 59.28 \\
\hline Cấp 2/Cấp 3 & 63 & 18.86 \\
\hline Trung cấp/Cao đẳng & 7 & 2.01 \\
\hline Đại học/Sau đại học & 9 & 2.69 \\
\hline \multicolumn{3}{|l|}{ Tình trạng hôn nhân } \\
\hline Độc thân & 8 & 2.40 \\
\hline Có gia đình sống với vợ/chồng, & 17 & 52.40 \\
\hline Ly dị/chia tay/ở góa & 151 & 45.21 \\
\hline \multicolumn{3}{|l|}{ Nghề nghiệp } \\
\hline Công nhân & 2 & 0.60 \\
\hline Nông dân & 15 & 4.49 \\
\hline Viên chức & 6 & 1.80 \\
\hline Buôn bán & 14 & 4.19 \\
\hline Già/ Hưu trí & 225 & 76.35 \\
\hline Thất nghiệp/nội trợ & 25 & 7.49 \\
\hline Khác & 17 & 5.09 \\
\hline \multicolumn{3}{|l|}{ Tập thể dục } \\
\hline Có & 84 & 25.15 \\
\hline Không & 250 & 74.85 \\
\hline \multicolumn{3}{|l|}{$\begin{array}{l}\text { Tình trạng dinh dưỡng (BMI) } \\
\text { Gầy: }<18,5 \mathrm{~kg} / \mathrm{m}^{2}\end{array}$} \\
\hline Bình thường : $18,5-24,99 \mathrm{~kg} / \mathrm{m}^{2}$ & 40 & 11.98 \\
\hline Thừa cân: $25-29,99 \mathrm{~kg} / \mathrm{m}^{2}$ & 242 & 72.46 \\
\hline \multirow[t]{2}{*}{ Béo phì: >=30 kg/m² } & 49 & 14.67 \\
\hline & 3 & 0.90 \\
\hline
\end{tabular}

Bảng 2: Đặc điểm lâm sàng các đối tựng tham gia nghiên cứu

\begin{tabular}{|c|c|c|}
\hline Đặc điểm lâm sàng & $\begin{array}{c}\text { Tần số } \\
\text { (n) }\end{array}$ & $\begin{array}{c}\text { Tỉ lệ } \\
\text { (\%) }\end{array}$ \\
\hline Kiếm soát được HA & 208 & 62.28 \\
Có & 126 & 37.72 \\
Không & 129 & 38.62 \\
\hline Tổn thương cơ quan đích & 205 & 61.38 \\
Có & & \\
Không & 62 & 18.56 \\
\hline Tiền sử THA & 272 & 81.44 \\
Có & & \\
Không & 62 & 19.46 \\
\hline Thời gian THA & 167 & 49.10 \\
$<1$ năm & 45 & 13.47 \\
1-5 năm & 60 & 17.96 \\
6-10 năm & \\
>10 năm &
\end{tabular}

Bảng 3. Điểm số 8 lĩnh vục sức khỏe của SF-36

\begin{tabular}{|l|c|c|c|}
\hline Lĩnh vụ̣c sức khỏe & $\begin{array}{c}\text { Điểm số } \\
(\mathbf{T B} \pm \text { ĐLC) }\end{array}$ & $\begin{array}{c}\text { Giá trị } \\
\text { nhỏ } \\
\text { nhất }\end{array}$ & $\begin{array}{c}\text { Giá trị } \\
\text { lớn } \\
\text { nhất }\end{array}$ \\
\hline Hoạt động chức năng & $15.9 \pm \mathbf{2 0 . 9}$ & 0 & 100 \\
\hline Giới hạn chức năng & $19.6 \pm 17.3$ & 0 & 100 \\
\hline Cảm nhận đau đớn & $38.4 \pm 21.3$ & 0 & 100 \\
\hline Đánh giá sức khỏe & $17.9 \pm 8.0$ & 0 & 92 \\
\hline Cảm nhận sức sống & $30.9 \pm 13.3$ & 0 & 75 \\
\hline Hoạt động xã hội & $30.4 \pm 13.6$ & 0 & 87.5 \\
\hline Giới hạn tâm lý & $27.9 \pm 20.6$ & 0 & 100 \\
\hline Tinh thần tống quát & $37.3 \pm 16.8$ & 5 & 90 \\
\hline
\end{tabular}

334 người bệnh tham gia nghiên cứu, chúng tôi nhận thấy điểm trung bình của 8 lĩnh vực sức khỏe dao động từ 15.9 đến 38.4 , tất cả các lĩnh vực sức khỏe có điểm số dưới 50.

Bảng 4. Điểm số 2 thành phần SKTC và SKTT của $S F-36$

\begin{tabular}{|l|c|c|c|}
\hline $\begin{array}{l}\text { Thành phần } \\
\text { sức khỏe }\end{array}$ & $\begin{array}{c}\text { Điểm số } \\
\text { (TB } \pm \text { ĐLC) }\end{array}$ & $\begin{array}{c}\text { Giá trị nhỏ } \\
\text { nhất }\end{array}$ & $\begin{array}{c}\text { Giá trị lớn } \\
\text { nhất }\end{array}$ \\
\hline $\begin{array}{l}\text { Sức khỏe thể } \\
\text { chất }\end{array}$ & $30.8 \pm 5.2$ & 16.8 & 56.7 \\
\hline $\begin{array}{l}\text { Sức khỏe } \\
\text { tinh thần }\end{array}$ & $32.0 \pm 7.1$ & 15.57 & 61.93 \\
\hline $\begin{array}{l}\text { Chất lượng } \\
\text { cuộc sống }\end{array}$ & $31.4 \pm 4.4$ & 22.3 & 45.63 \\
\hline
\end{tabular}


Điểm số trung bình của sức khỏe thể chất là $30.8 \pm 5.2$ thấp hơn điểm số của sức khỏe tinh thần là $32.0 \pm 7.1$

\section{BÀN LUẬN}

Qua khảo sát 334 người bệnh tham gia nghiên cứu, chúng tôi nhận thấy có 228 người bệnh là nữ (68.26\%) và 106 người bệnh nam (31.74\%).Tỉ lệ nữ giới nhập viện do bệnh THA tại khoa Tim Mạch nhiều hơn so với nam giới. Nghiên cứu này tương tự với một số nghiên cứu khác như: Nghiên cứu của tác giả Trần Kim Trang năm 2010 thì nữ giới chiếm $63.1 \%$ và nam chiếm $36.9 \%$ [12].

Đa số người bệnh THA tập trung nhóm tuổi trên 60 chiếm gần $80 \%$ nhiều nhất ở nhóm tuổi 60 79 chiếm $53.29 \%$ và nhóm $>=80$ chiếm $25.75 \%$. Nghiên cứu Fabiana và cộng sự tại Brazil năm 2013 thì nhóm tuổi $>60$ chiếm tỉ lệ cao hơn $83.1 \%$ [2].

Người bệnh có gia đình đang sống chung với vợ hoặc chồng chiếm tỷ lệ cao nhất $52.4 \%$, thấp nhất là độc thân chiếm $2.4 \%$ và ly dị, ly thân hoặc ở góa chiếm $45.21 \%$.Kết quả nghiên cứu này thấp hơn so với nghiên cứu của Erin Stanley và cộng sự tại Mỹ năm 2011 tỷ lệ người bệnh đã kết hôn chiếm $68.3 \%$ [1].

Về trình độ học vấn đa số người bệnh THA có trình độ học vấn thấp biết đọc, viết và cấp 1 chiếm tỷ lệ cao $59.28 \%, 17.07 \%$ mù chữ, $18.86 \%$ cấp 2 cấp $3,4.79 \%$ có trình độ cao đẳng, đại học và sau đại học, nghề nghiệp chủ yếu của người bệnh là thất nghiệp và nông dân. Kết quả nghiên cứu của chúng tôi tương tự kết quả nghiên cứu của Khaw W. F tại Malaysia năm 2011 người bệnh có trình độ học vấn biết đọc, viết cấp 1 chiếm tỷ lệ cao nhất 54.7\% [5].

Đa số người bệnh kiểm soát được $\mathrm{HA}$ chiếm $62.28 \%$ và không kiểm soát được $\mathrm{HA}$ chiếm tỷ lệ $37.72 \%$.Trong nghiên cứu của Youssef và cộng sự tại Ai Cập năm 2005 [13] thì tỷ lệ người bệnh THA được kiểm soát chiếm tỷ lệ thấp $53.2 \%$. \%. Chúng tôi nhận thấy rằng sự khác nhau về kiểm soát huyết áp có thể do sự khác nhau về văn hóa, nhận thức, điều kiện sống và hành vi liên quan.

Đối với tổn thương cơ quan đích, trong nghiên cứu của chúng tôi thì tỷ lệ người bệnh không có tổn thương cơ quan đích chiếm tỉ lệ cao $61.38 \%$, người bệnh có tổn thương cơ quan đích $38.62 \%$.nghiên cứu của chúng tôi tương tự như kêt quả nghiên cứu Youssef và cộng sự tại Ai Cập năm 2005 [13]. Người bệnh không có tổn thương cơ quan đích chiếm $65.5 \%$. Chúng tôi nhận thấy rằng người bệnh không có tổn thương cơ quan đích chiếm tỷ lệ cao hơn có thể do người bệnh kiểm soát tốt được HA, hệ thống điều trị và chăm sóc tại khoa tốt.

Về tiền sử và thời gian THA, phần lớn người bệnh không có tiền sử THA chiếm $81.44 \%$ và có tiền sử THA chỉ chiếm $18.56 \%$, người bệnh có thời gian THA từ 1-5 năm chiếm tỷ lệ cao nhất $49.10 \%$ so với thời gian THA <1 năm chiếm $19.46 \%$, 6-10 năm $13.47 \%$ và $>10$ năm chiếm $17.96 \%$.Kết quả nghiên cứu này tương tự kết quả nghiên cứu của Fabiana và cộng sự tại Brazil năm 2013, tỷ lệ người bệnh có thời gian THA từ 1-5 năm chiếm $41.5 \%$ cao hơn so với nhóm thời gian khác [2].

Kết quả khảo sát cho thấy người bệnh THA có điểm số trên các lĩnh vực sức khỏe đều thấp $<50$ điểm, thấp nhất là hoạt động chức năng $15.9 \pm 20.9$, cao nhất là cảm nhận sự đau đớn $38.4 \pm 21$.3.

Điểm số cho lĩnh vực hoạt động chức năng là $15.9 \pm 20.9$. Kết quả nghiên cứu rất khác so với những nghiên cứu trước. Trong nghiên cứu của Michelle tại Brazil năm 2012 điểm trung bình cho lĩnh vực này $58.7 \pm 27.8$ [9]. Nghiên cứu của Erin Stanley và cộng sựtại New Orleansnăm 2011 trung

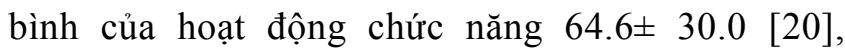
nghiên cứu khác của Khaw W. F tại Malaysia năm 2011 thì điểm trung bình của lĩnh vực hoạt động chức năng 73.15 27.68 [5]. So sánh kết quả điểm trung bình về lĩnh vực hoạt động chức năng, rõ ràng 
nghiên cứu của chúng tôi có điểm số thấp hơn so với nghiên cứu ở Brazil, Mỹ và Malaysia. Điểm số thấp trong nghiên cứu của chúng tôi có thể do người bệnh đa số lớn tuổi, thời gian THA lâu xãy ra nhiều biến chứng nên ảnh hưởng đến khả năng vận động của người bệnh. Người bệnh đôi khi bị hạn chế khi thực hiện tất cả hoạt động chức năng bao gồm tự tắm rửa hoặc thay quần áo.

Điểm số giới hạn hoạt động do khiếm khuyết chức năng, lĩnh vực này có điểm số thấp sẽ làm cho người bệnh bị trở ngại trong công việc hoặc sinh hoạt hàng ngày do tình trạng sức khỏe chức năng, với điểm số trung bình $19.6 \pm 17.3$, so sánh kết quả này với nghiên cứu khác cho kết quả khác nhau về điểm số, được nghiên cứu bởi Gavin và cộng sự tại Mỹ năm 2012 với giá trị trung bình là $68.0 \pm 2.0$ [3]. Trong nghiên cứu của Mohammed tại Saudi Arabia năm 2002 điểm số $43.93 \pm 41.24$ [10], sự hiện diện của tổn thương cơ quan đích cũng ảnh hưởng tích cực đến giới hạn hoạt động của người bệnh.

Lĩnh vực cảm nhận về sự đau đớn của người bệnh với điểm số có giá trị trung bình $38.4 \pm 21.3$. Trong những nghiên cứu khác điểm số lĩnh vực cảm nhận sự đau đớn cho kết quả cao hơn như nghiên

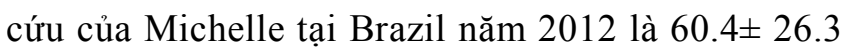
[9], nghiên cứu của Michael $\mathrm{O}$ và cộng sự tại Nigeria năm 2009 điểm số là $76.28 \pm 30.17$ [41]. THA là bệnh mãn tính, bệnh được cho là kẻ giết người thầm lặng và đôi khi không có triệu chứng, không có dấu hiệu nào báo trước vì vậy đau không phải là triệu chứng đi kèm với bệnh THA, mà đau thường xuất hiện khi người bệnh có các bệnh lý khác đi kèm hoặc có một số biến chứng tim mạch khác như nhồi máu cơ tim cấp. Như vậy, tổn thương cơ quan đích và các yếu tố nguy cơ tim mạch có thể là làm nặng thêm cơn đau đớn cho người bệnh và làm cho lĩnh vực này có điểm số thấp.

Lĩnh vực đánh gía sức khỏe có điểm số trung bình $17.9 \pm 8.0$, kết quả nghiên cứu của Monika $\mathrm{Z}$ và cộng sự tại $\mathrm{Ba}$ Lan năm 2012 giá trị trung bình là $44.39 \pm 20.53[11]$ và nghiên cứu của Mamas và cộng sự ở Brazil năm 2012 điểm số lĩnh vực này $60.7 \pm 22.7$ [6]. Chúng tôi nhận thấy rằng kết quả này có thể xãy ra như kết quả biểu hiện lâm sàng liên quan đến nguyên nhân và điều trị bệnh tăng huyết áp, nhìn chung bệnh THA được nhận thấy là một tình trạng nghiêm trọng và điều này được khẳng định trong nghiên cứu của chúng tôi.

Lĩnh vực thứ năm sức khỏe liên quan đến cảm nhận cuộc sống, lĩnh vực này có điểm số trung bình $30.9 \pm 13.3$. Kết quả này rất thấp so với nghiên cứu của Khaw ở Malaysia năm 2011 thì điểm số lĩnh vực này là $58.39 \pm 19.45$ [9]. Điểm số thấp chỉ ra sự suy giảm trong cảm nhận cuộc sống của người bệnh THA có liên quan đến tâm trạng của người bệnh, người bệnh lúc nào cũng cảm thấy ưu tư buồn và mệt mỏi.Trong nghiên cứu của Erin Stanley và cộng sự tại Mỹ năm 2011 thì điểm trung bình của lĩnh vực này $53.6 \pm 26.5$ [1]. Chúng tôi nhận thấy rằng bệnh THA gây trở ngại cho tình trạng thể chất của người bệnh như mệt mỏi liên quan đến tuổi tác và thời gian mắc bệnh.

Lĩnh vực sáu: sức khỏe liên quan đến hoạt động xã hội với giá trị trung bình $30.4 \pm$ 13.6. Kết quả nghiên cứu này thấp hơn so với nghiên cứu của Monika Z tại Ba Lan năm 2012 điểm số là 65.42 \pm 26.32 [11]. Huyết áp ảnh hưởng đến người bệnh tham gia các hoạt động xã hội như thăm viếng người thân bạn bè hay hàng xóm, do đó sự cần thiết phải thay đổi lối sống bao gồm cả thói quen ăn uống của người bệnh để kiểm soát được huyết áp. Như vậy, tình trạng bệnh THA có thể dẫn đến sự suy giảm trong các mối quan hệ xã hội, các hoạt động giải trí và vui chơi, dẫn đến suy giảm chất lượng cuộc sống của người bệnh.

Điểm trung bình của lĩnh vực giới hạn tâm lý là $27.9 \pm 20.6$, điểm số thấp cho thấy người bệnh bị trở ngại trong công việc hoặc sinh hoạt hàng 
ngày do tình trạng sức khỏe tâm lý làm suy giảm chất lượng cuộc sống của người bệnh. HA tăng thường do cảm xúc và căng thẳng liên quan, người bệnh dường như không biết cách để giảm lo âu căng thẳng. Người bệnh thường cho rằng cảm xúc của họ phụ thuộc vào người khác. Điều này có thể dẫn đến sự suy giảm trong chất lượng cuộc sống.

Điểm số lĩnh vực sức khỏe tinh thần tổng quát là $37.3 \pm 16.8$, trong nghiên cứu của chúng tôi điểm số này cao thứ nhì trong tám lĩnh vực sức khỏe nhưng cũng thấp hơn so với nghiên cứu của tác giả Maria và cộng sự ở Brazil năm 2013 là $66.6 \pm 21.0$ [7]. Tăng huyết áp là bệnh mạn tính do đó ảnh hưởng trực tiếp đến cuộc sống của người bệnh, người bệnh đa số lớn tuổi họ luôn có sự lo lắng về bệnh tật dẫn đến cảm xúc tiêu cực như trầm cảm và lo âu.

Chúng tôi nhận thấy điểm số SKTC và SKTT trong nghiên cứu của chúng tôi $(30.8 \pm 5.2,32.0 \pm$ 7.1) thấp hơn so với nghiên cứu của Gavin $\mathrm{W}$ và

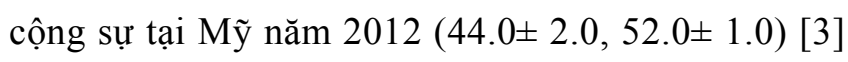
và nghiên cứu của tác giả Mohammed $\mathrm{S}$ ở Saudi Arabia năm 2002 thì điểm trung bình SKTC và SKTT là $(39.31 \pm 12.80,43.69 \pm 10.70)$ [10]. Điểm số thấp hơn so với nghiên cứu khác, có thể do nghiên cứu của chúng tôi người bệnh lớn tuổi $>60$ chiếm tỉ lệ cao hơn, nữ chiếm tỉ lệ cao hơn so với nghiên cứu trên. Tuổi $>60$ là nhóm tuổi được nhận định CLCS giảm đi, BN nữ nhiều hơn là đối tượng thường được cho là có khả năng chịu đựng thấp dễ bị lo âu, căng thẳng nên ảnh hưởng đến CLCS.

\section{KẾT LUẬN}

Dù được biết là một bệnh thường không có triệu chứng, nhưng THA làm cho CLCS giảm dần do biến chứng của bệnh, bệnh lý kèm theo, tác dụng phụ của thuốc điều trị và nhận thức bệnh tật của người bệnhDo đó, cần lưu tâm hơn đến CLCS của người THA.

\section{TÀI LIỆU THAM KHẢO}

1. Erin Stanley, MPH, Paul Muntner, PhD, MHS, Richard N. Re, MD, Edward D. Frohlich, MD,Elizabeth Holt, PhD, MPH, Marie A. Krousel-Wood, MD, MSPH (2011), "Quality of Life in Hypertensive Clinic Patients Following Hurricane Katrina", The Ochsner Journal , pp. 226-231.

2. Fabiana Coriolano Ribeiro Cavalcanti, Eduardo Tavares Gomes, Eugênia Velludo Veiga, Simone Maria Muniz da Silva Bezerra (2013), “ Profile of health and quality of life assement of hypertensive patients by the specific intrument MinichalBrazil",J Nurs UFPE on line, Recife, 7(12), pp.6732-6740.

3. Gavin W. Lambert, Dagmara Hering, Murray D, et, al (2012), "Health-Related Quality of Life After Renal Denervation in Patients With Treatment-Resistant Hypertension", Hypertension, pp.1479-1484.

4. Hội tim mạch quốc gia Việt Nam (2010), "Tăng huyết áp - kẻ giết người thầm lặng”. Tạp chí tim mạch học Việt Nam, 54(4).

5. Khaw W. F, Hassan S. T. S, Latiffah A. L (2011), "Health-related Quality of Life among Hypertensive patients Compared with General Population Norms”,J. Med. Sci. 11(2), pp.84-89.

6. Mamas Theodorou, Daphne Kaitelidou, Petros Galanis, Nicos Middleton,

Panagiotis Theodorou, Panagiotis Stafylas, Olga Siskou, Nikos Maniadakis (2011), “ Quality of Life Measurement in Patients with Hypertension in Cyprus",Hellenic J Cardiol, pp. 407-415.

7. Maria Virgínia de Carvalho1, Liza Batista Siqueira2, et, al(2013), "The Influence of Hypertension on Quality of Life",Arq Bras Cardiol, 100(2), pp.164-174.

8. Michael O Ogunlana, Babatunde Adedokun, Magbagbeola D Dairo and 
Nse A Odunaiya (2009), "Profile and predictor of health-related quality of life among hypertensive patients in south-western Nigeria”,BMC Cardiovascular Disorders.

9. Michelle Adler Normando Carvalho; Isabela Bispo Santos Silva, et,al ( 2012), “ Quality of Life of hypertensive patients and comparison of two instruments of HRQOL measure",Arq. Bras. Cardiol, vol.98 no.5

10. Mohammed S. Al-Ghamdi, FFCM (KFU, et, al (2002), "Quality of life in a sample of hypertensive patients attending primary health care facilities in Al-Khobar, Saudi Arabia”,J
Family Community Med, 9(1), pp.25-32.

11. Monika Zygmuntowicz, Aleksander Owczarek, Adam Elibol, Jerzy Chudek1 (2012), " Comorbidities and the quality of life in hypertensive patients",Polskie Archiwum Medycyny Wewnetrznej, pp.333-340.

12. Trần Kim Trang(2010), “Chất lượng cuộc sống ở người tăng huyết áp”, Tạp chí y học, Đại học Y DượcTP. Hồ Chí Minh, 15(1), tr.104-111.

13.Youssef. R. M, Moubarak I. I and Kamel M.I (2005), "Factors affecting the quality of life of hypertensive patients",Eastern Mediterranean Health Journal, Vol. 11. 